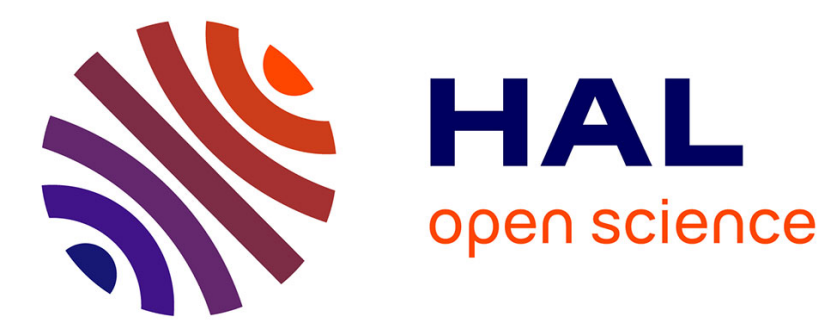

\title{
Experimental study of industrial wastewater treatment by freezing
}

Thouaiba Htira, Claudia Cogné, Emilie Gagniere, Denis Mangin

\section{To cite this version:}

Thouaiba Htira, Claudia Cogné, Emilie Gagniere, Denis Mangin. Experimental study of industrial wastewater treatment by freezing. Journal of Water Process Engineering, 2018, 23, pp.292-298. 10.1016/j.jwpe.2018.04.013 . hal-01886291

\section{HAL Id: hal-01886291 \\ https://hal.science/hal-01886291}

Submitted on 2 Oct 2018

HAL is a multi-disciplinary open access archive for the deposit and dissemination of scientific research documents, whether they are published or not. The documents may come from teaching and research institutions in France or abroad, or from public or private research centers.
L'archive ouverte pluridisciplinaire HAL, est destinée au dépôt et à la diffusion de documents scientifiques de niveau recherche, publiés ou non, émanant des établissements d'enseignement et de recherche français ou étrangers, des laboratoires publics ou privés. 


\title{
Experimental study of industrial wastewater treatment by freezing
}

\author{
Thouaïba HTIRA, Claudia COGNÉ, Emilie GAGNIÈRE, Denis MANGIN*
}

Univ Lyon, Université Claude Bernard Lyon 1, CNRS, LAGEP UMR 5007, 43 boulevard du 11 novembre 1918, F69100, VILLEURBANNE, France

*denis.mangin@univ-lyon1.fr

\begin{abstract}
This work aims to study an industrial wastewater treatment process by melt crystallization on a cold wall. A binary solution of water/acetone was chosen as model effluent. A parametric study of the wastewater treatment process was performed by means of an experimental design. The process was conducted in a static mode and the impurity concentration in the ice was analyzed after each freezing cycle. The process required applying very precise conditions and the ice concentration mainly depended on the initial solution concentration and on the applied cooling rate. The ice microstructure was also characterized by optical microscopy in a cold chamber and gave insights into the mechanism of impurity incorporation: the liquid inclusions were localized under the form of solution pockets at low growth rate or between the polycrystals at higher growth rate.
\end{abstract}

Keywords: wastewater treatment, static melt crystallization, experimental design, microscopic analyzes

\section{Introduction}

Melt crystallization technology is well-known and has proved its efficiency in many industrial applications, particularly for freeze concentration in food industries (Deshpande et al., 1984), where the product flavors are temperature sensitive and for isomeric separation (Beierling and Ruether, 2012). A recent review proposes discussion on the different freeze crystallization that can be applied for the treatment of reverse osmosis brines (Randall et al., 2015). However, the technique has not yet been applied at industrial scale for wastewater treatment. This absence is 
probably due to misconceptions about this technique, especially concerning water purity or energy consumption. One of the first studies dealing with melt crystallization applied for wastewater treatment was done by Halde (Halde, 1980). The author demonstrated the feasibility of freeze wastewater treatment of solutions and suspensions, but the process could not be extrapolated to industrial scale. Since this study, the improvement of melt crystallization technology (Klein et al., 1994) helps to bring out the advantages of the treatment (Lorain et al., 2000) with batch (Kim, 2006) or continuous (Wakisaka et al., 2001) pilot scale processes.

Moreover, the environmental hazards are now better apprehended and the standards for effluent discharge are getting more and more restricted. In this context, wastewater treatment by freeze concentration appears to be an interesting technology with low environmental impact (Ulrich, 2004). Indeed, energy consumption is low compared to distillation process (latent heat of water vaporization is seven times higher than latent heat of ice fusion), no additional chemical products are needed and the produced ice crystals can be used as cold storage (Egolf et al., 2008). In addition, the implementation of a freezing step in wastewater treatment units presents two main advantages: (i) the high concentration in pollutants reached in the liquid effluent allows an easier post treatment of this effluent (either by advanced oxidation process or by incineration with a strong reduction of energy consumption) and (ii) the purity of the recovered aqueous effluent gets closer to the discharge standards.

The freeze crystallization can be classified into two groups, direct freezing and indirect freezing. In direct freezing, the refrigerant used to cool the solution is mixed directly with the brine. In indirect freeze concentration (i.e. with cooling performed across the wall of a heat exchanger), two main techniques have been investigated in the literature: (i) the process can work with suspensions of ice crystals, generally formed by scraping the ice layer deposited on the heat exchanger surface (Matsuoka et al., 1996) or (ii) it can consist in the formation and growth of an ice layer on the exchanger surface, which is melt in a following step, to recover the purified aqueous solution (Miyawaki et al., 2005; Mandri et al., 2011; Rich et al., 2010; Rich et al., 2012). The first technique 
has several advantages, as it can be operated in continuous mode and generally gives good ice crystal purity. However, two additional steps of filtration and washing are required to achieve the treatment. The second technology has retained our attention, because the separation between ice and concentrated wastewater is easier and does not require other unit operations. Crystallization on cold surface can be achieved in stagnant (Shirai et al., 1998) solution (static melt crystallization) or in dynamic mode (Shirai et al., 1999; Jusoh et al., 2008) with a falling film of solution or a circulation of solution. Cold surfaces can be flat (Hirata et al., 2002) or cylindrical. Nucleation is a stochastic process and requires obviously to reach the metastable zone limit (Randall et al., 2012). The material and the surface state are thus key factors of the nucleation (Haasner et al., 2001). If the influence of the operating parameters has widely been studied (Jiang et al., 2014) the phenomena occurring during the crystallization have not yet been accurately explained.

This work aims to operate with very precise conditions the process in order to understand the intrinsic phenomena, particularly the impurity incorporation mechanism. In that purpose the nucleation was overcome by forming a seed layer to avoid the rapid uncontrolled growth that occurs immediately after nucleation. The solid-liquid phase diagram was firstly established, in order to define the working domain, in terms of concentrations and temperatures. The second part of the work was focused on the static melt crystallization process, using a mixture of water and acetone as wastewater model. This model system is not linked to immediate practical application but the methods and findings developed in the paper can be extended to any system. An experimental design was used to quantify the influence of the parameters and their interactions on the acetone concentration in the ice layer. Finally, optical microscopic analyses of the ice structure were carried out to visualize the incorporation mechanisms.

\section{Nomenclature}

$\mathrm{C}_{0} \quad$ Initial solution concentration 
$\mathrm{T}_{\text {eq }} \quad$ Equilibrium temperature

$V_{R} \quad$ Cooling ramp

$V_{C R} \quad$ Ice growth rate

$\Delta \mathrm{T} \quad$ temperature difference between the cold tube and the tank double jacket

$w_{\text {acetone }}$ mass fraction of acetone in the solution

\section{Experimental methods}

\subsection{Thermodynamic data}

The determination of the solid/liquid phase diagram of the binary system water/acetone is essential to define the operating conditions of the crystallization process and to delimit the working domains which avoid the formation of undesired solid forms. The phase diagram was achieved using two methods, the Differential Scanning Calorimetry (DSC) and a synthetic method, as described in a previous work dedicated to the establishment of the binary water/propionic acid phase diagram (Htira et al., 2016).

The calorimeter used in this study was a Thermal Analysis instruments (TA Q200). Samples (10 to 20 $\mathrm{mg}$ ) of mixtures prepared at varying composition were weighed with a METTLER balance with an accuracy of $0.01 \mathrm{mg}$ and then placed in sealed aluminum pans. To determine the phase change temperature, the experiments were performed according to the following program: (a) isotherm at $5^{\circ} \mathrm{C}$, (b) cooling rate at $10^{\circ} \mathrm{C} \mathrm{min}^{-1}$, (c) isotherm at $-70^{\circ} \mathrm{C}$ during 5 minutes, (d) heating rate at $1^{\circ} \mathrm{C}$ $\min ^{-1},(e)$ idem steps $a, b$ and $c,(f)$ heating rate at $5^{\circ} \mathrm{C} \mathrm{min}^{-1},(\mathrm{~g})$ idem steps $\mathrm{a}, \mathrm{b}$ and $\mathrm{c}$, (h) heating rate at $10^{\circ} \mathrm{C} \mathrm{min}^{-1}$. The results reported in this work correspond to data during the heating phase (step $d, f$ and $h$ ). All DSC curves were normalized with respect to the sample mass.

For the synthetic method, solution was cooled until solidification and heated until crystals fusion by analyzing the evolution of the solution temperature. The solution in the double jacketed vessel was homogenized with a magnetic stirrer. Solid-liquid phase diagram was then determined by monitoring temperature using a calibrated Pt100 resistance. 
The synthetic method was used to consolidate the liquidus temperatures measured by Differential Scanning Calorimetry. Our experimental results were then compared to the literature data (Rosso and Carbonnel, 1975).

\subsection{Experimental setup}

Figure 1 shows the scheme of the experimental setup and a photo focused on the crystallizer used for wastewater treatment. The apparatus consisted of a vertical stainless steel tube (1) plunged inside a cylindrical glass tank (5) filled with $0.3 \mathrm{~L}$ of solution (3). The freezing layer (4) developped on the wall of the vertical tube. The temperatures inside the tube and in the double jacket of the tank (5) were controlled by means of two thermostatic baths ( 6 and 7) filled with a water-ethylene glycol mixture (ethylene glycol mass fraction of $40 \% \mathrm{w} / \mathrm{w}$ ).

The temperatures of the bulk solution and of the coolant inlet and outlet were measured with a set of six Pt100 sensors and were recorded via a data acquisition system (National Instrument) in a computer. After calibration, the error in temperature measurements was within the $\pm 0.05 \mathrm{~K}$ range. The bottom and the top parts of the tube were covered with Teflon band to avoid crystallization and prevent edge effect, as shown by the work of Chen (Chen et al., 1999). The tube external diameter was $2 \mathrm{~cm}$. The efficient tube length covered with the ice layer was equal to $25 \mathrm{~cm}$. The inside diameter of the jacketed tank measured $4 \mathrm{~cm}$, leading to an annular space available for the solution of $1 \mathrm{~cm}$ in width.

A camera, equipped with a video zoom, was used to film the ice layer and measure its growth rate. The images of the ice layer growth were registered every $2 \mathrm{~min}$ and analyzed with image J software. The precision in the ice thickness measurement was evaluated as being equal to $2.10^{-4} \mathrm{~m}$. This visual method was used to verify the linearity of the ice layer growth (especially at the earlier step of the growth). But since the ice thickness was not uniform along the tube, the mean growth rate of the ice layer was calculated with the total mass of ice produced and the total duration of the experiment. 


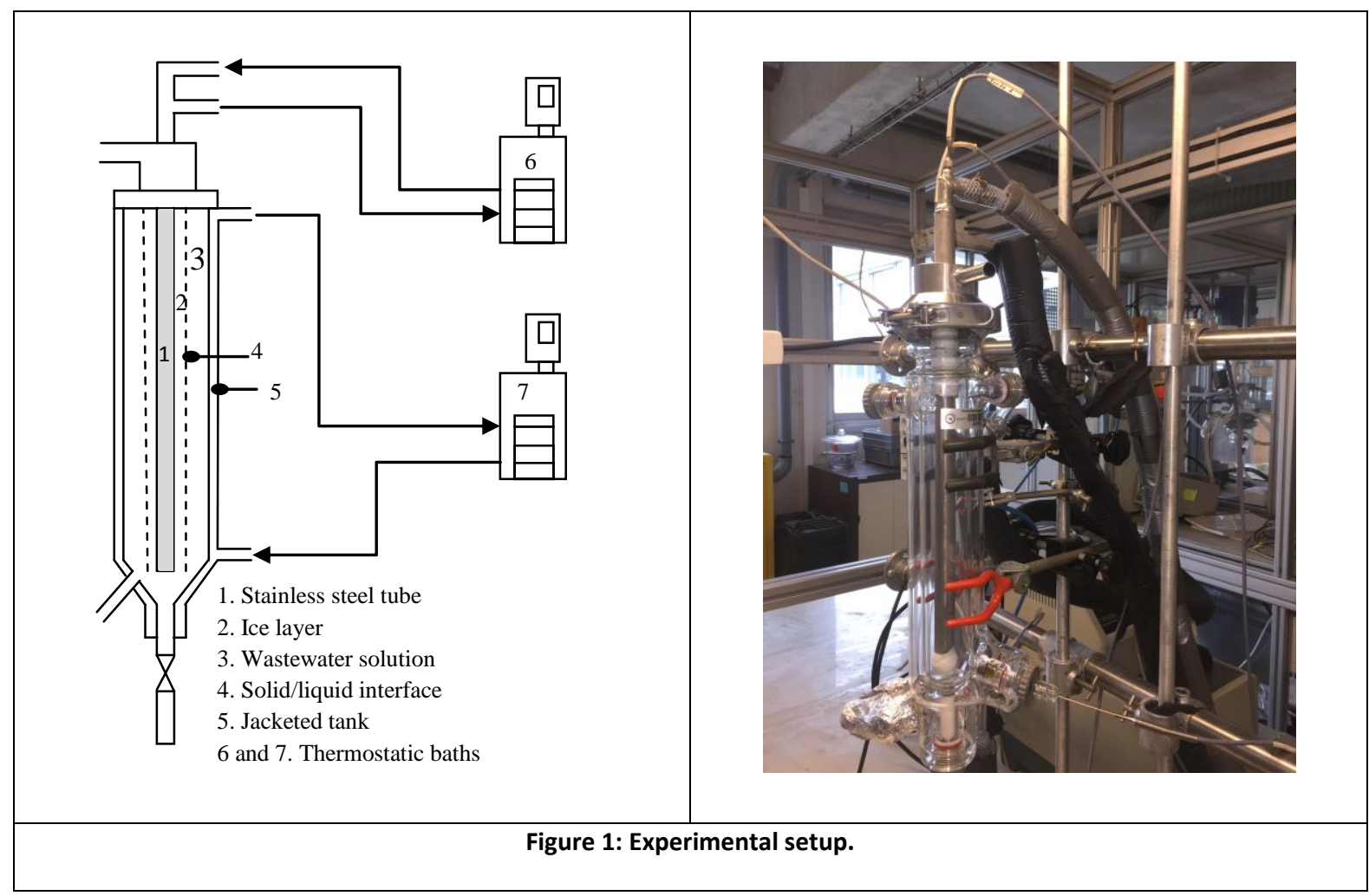

\subsection{Experimental procedure}

\subsubsection{Freezing step}

The ice layer formed is contaminated by the solute during the freezing step for kinetic reasons, and by the solution at the ice/solution interface during the crystalline growth. Therefore, the freezing process involved various steps that reduced this contamination. The freezing was initialized by forming a seed layer of pure water. This seeding step was conducted to avoid the stochastic aspect of primary nucleation. The initialization was done as follows: the tube was cooled to $-6^{\circ} \mathrm{C}$ and plunged few seconds in distilled water in order to form a seed layer (mean width of $0.5 \mathrm{~mm}$ ) on the surface of the tube; the tube was next quickly set to the chosen initial temperature of the freezing step and introduced in the glass tank filled with the solution to be treated. The freezing step was then started. Parallel linear cooling rates were applied in both the cold tube and the double jacket of the glass tank. The same $\Delta T$ was then applied between the tube and the tank double-jacket all along the experiment. The effect of $\Delta T$ on the ice purity was highlighted in previous works (Mandri 
et al., 2011 ; Rich et al., 2010). It was attributed to the amplification of the convection currents by the temperature gradients.

At the end of the freezing, the residual solution was drained through the bottom draw-off tap. Since our study was focused on the layer formation, a simple draining was finally carried out by raising the temperature of the double jacket to $5^{\circ} \mathrm{C}$ for 1 hour. This step allowed washing the ice layer by slightly melting its outer surface. Let us note that this washing step does not correspond to the so-called sweating step, which allows a deep purification of the ice layer. The remaining ice layer was finally recovered by completely melting it. The melted purified ice was analyzed by gas chromatography to measure the impurity concentration.

\subsubsection{Factorial design}

A factorial design was performed to quantify the role of the process parameters on the ice purity ( $C_{a}$ being the acetone concentration in the ice) and the average ice growth rate $\left(V_{c r}\right)$. The investigated parameters were the initial solute concentration $\left(C_{0}\right)$, the cooling rate $\left(V_{r}\right)$ and the temperature difference between the cold tube and the tank double jacket $(\Delta \mathrm{T}$, maintained constant during each experiment by applying two parallel cooling rates in the tube and the tank double jacket-same slopes with a temperature difference of $\Delta T$ ). The working conditions and the two responses of the different runs discussed in this article are summarized in table 1 . The studied parameters were identified in previous works (Mandri et al., 2011 ; Rich et al., 2010). The working domain was chosen thanks to these previous works and adjusted through preliminary experiments.

\begin{tabular}{|c|c|c|c|c|c|c|}
\hline & Run & $\begin{array}{l}\Delta \mathrm{T} \\
\left({ }^{\circ} \mathrm{C}\right)\end{array}$ & $\begin{array}{c}V_{R} \\
\left({ }^{\circ} \mathrm{C} \cdot \mathrm{h}^{-1}\right)\end{array}$ & $\begin{array}{c}C_{0} \\
\text { (\% wt) }\end{array}$ & $\begin{array}{c}\mathrm{C}_{\mathrm{a}} \\
\left(\mathrm{g} \cdot \mathrm{L}^{-1}\right)\end{array}$ & $\begin{array}{c}V_{c r} \\
\left(m m \cdot h^{-1}\right)\end{array}$ \\
\hline \multirow{8}{*}{$\begin{array}{l}\text { Experimental } \\
\text { design }\end{array}$} & 1 & 2.1 & 0.05 & 5 & 13.37 & 0.399 \\
\hline & 2 & 2.1 & 0.1 & 5 & 14.50 & 0.752 \\
\hline & 3 & 5.2 & 0.1 & 5 & 10.77 & 0.525 \\
\hline & 4 & 5.2 & 0.05 & 5 & 7.86 & 0.292 \\
\hline & 5 & 2.1 & 0.1 & 20 & 71.85 & 0.288 \\
\hline & 6 & 2.1 & 0.05 & 20 & 74.19 & 0.162 \\
\hline & 7 & 5.2 & 0.1 & 20 & 78.88 & 0.184 \\
\hline & 8 & 5.2 & 0.05 & 20 & 58.01 & 0.089 \\
\hline
\end{tabular}




\begin{tabular}{|c|c|c|c|c|c|c|}
\hline \multirow{2}{*}{$\begin{array}{c}\text { Repetition at } \\
\text { the center of } \\
\text { the domain }\end{array}$} & 9 & 3.7 & 0.075 & 12.5 & 39.80 & 0.280 \\
\cline { 2 - 7 } & 10 & 3.7 & 0.075 & 12.5 & 45.42 & 0.290 \\
\hline \multirow{3}{*}{\begin{tabular}{c} 
Check points \\
\cline { 2 - 7 }
\end{tabular}} & 11 & 3.7 & 0.075 & 12.5 & 43.67 & 0.280 \\
\hline \multirow{4}{*}{$\begin{array}{c}\text { Complementary } \\
\text { runs }\end{array}$} & 12 & 4.2 & 0.08 & 7.0 & 16.28 & 0.320 \\
\cline { 2 - 7 } & 14 & 4.0 & 0.07 & 10 & 31.81 & 0.225 \\
\cline { 2 - 7 } & 16 & 5.0 & 0.02 & 5 & 3.92 & 0.073 \\
\cline { 2 - 7 } & 17 & 5.0 & 0.025 & 10 & 6.09 & 0.059 \\
\hline
\end{tabular}

Parametric simulation follows a $2^{3}$ factorial test plan using dimensionless parameters. Each parameter has a low and high level, respectively -1 and +1 . The low and high factor values chosen for this study were selected in the operating range covered by the parameters: $C_{0}$ was taken between $5 \%$ and $20 \%$ in weight (which corresponds to an initial concentration between 49.78 g. $\mathrm{L}^{-1}$ and 196.12 g. $\left.\mathrm{L}^{-1}\right), \Delta \mathrm{T}$ between $2.1^{\circ} \mathrm{C}$ and $5.2^{\circ} \mathrm{C}$ and $\mathrm{V}_{\mathrm{r}}$ between $0.05^{\circ} \mathrm{C} \cdot \mathrm{h}^{-1}$ and $0.1^{\circ} \mathrm{C} . \mathrm{h}^{-1}$. For each response, the mathematical model was given by the following equation (Eq. 1):

$$
y=b_{0}+\sum_{i=1}^{m} b_{i} x_{i}+\sum_{i, j=1}^{m} b_{i j} x_{i} x_{j}+\sum_{i, j, k=1}^{m} b_{i j k} x_{i} x_{j} x_{k}+\ldots
$$

$y$ is the response, $b_{i}$ are the parameters related to the main variables $x_{i}, b_{i j}$ and $b_{i j k}$ are the parameters related to interactions between two and three variables, respectively.

In addition, the experimental runs were conducted by respecting the following requirements:

- The layer thickness evolution was linear. In particular, the initial temperatures had to be precisely chosen in order to avoid too fast or too slow ice growth at the beginning of the freezing.

- The mass of the collected ice was similar in each run, around $30 \mathrm{~g}$. This low amount was purposely chosen, such that the acetone concentration in the solution remained almost unchanged.

- The temperature difference between the cold wall and the tank double jacket was constant all over each run. Thus, the slopes of the cooling rates of the two refrigerant baths were the same. 


\subsection{Ice concentration analysis}

The melted ice samples were analyzed by gas chromatography, with a Shimadzu GC2010 plus device to measure acetone concentration $\left(C_{a}\right)$.

The column was of $30 \mathrm{~m}$ length and $0.25 \mathrm{~mm}$ diameter. The column was polar with ethylene glycol as stationary phase. Injection temperature was fixed at $130^{\circ} \mathrm{C}$. A heating ramp of $10^{\circ} \mathrm{C} \cdot \mathrm{min}^{-1}$ was applied in the oven from 35 to $125^{\circ} \mathrm{C}$. After the components have been separated, they pass over a Flame Ionization Detector (FID) at $200^{\circ} \mathrm{C}$. The injection amount was $2 \mu \mathrm{L}$ and acetone retention time was around 3.7 minutes.

An external calibration was previously carried out between 1 and $80 \mathrm{~g} \cdot \mathrm{L}^{-1}$ of acetone concentration. The calibration curve (acetone concentration vs pic area) was linear in this concentration range, with a determination coefficient equal to 0.9967 . The measurement error in ice impurity concentration was estimated at $\pm 0.31 \mathrm{~g} \cdot \mathrm{L}^{-1}$.

\subsection{Microscopic analysis}

Samples of ice were carefully taken out from the layer formed on the tube surface and put in an isothermal cold box. The samples were then rapidly transported to a cold room kept at $-25^{\circ} \mathrm{C}$ for their preparation and observation. Each cubic sample (a few centimeters long) was first stuck on a metallic support and smoothed down by means of a microtome (Leica SM2000R) to obtain a flat surface representative of the interior of the ice layer with a roughness lower than $1 \mu \mathrm{m}$. An optical microscope (Leica MZ12) with an optical fiber providing episcopic coaxial lighting (Caillet et al., 2003) was used in the cold room for the observation of the different samples.

\section{Results and discussion}

\subsection{Thermodynamic data}

The experimental phase diagram (Figure 2) was built from both the Differential Scanning Calorimetry (blue squares) and synthetic methods (red circular points). The measures are in good 
agreement with the literature data (Rosso and Carbonnel, 1975) represented in continuous black lines. The phase diagram exhibits an eutectic behavior (not represented in Figure 2), a hydrate compound with a peritectic behavior and a demixion zone. Table 2 gives the coordinate of these points or zone.

Table 2: Temperature and composition of the remarkable points for the water/acetone binary system

\begin{tabular}{lcc} 
Compound nature & $\mathbf{w}_{\text {acetone }}(\mathbf{\%} \mathbf{~ w t})$ & Temperature $\left({ }^{\circ} \mathbf{C}\right)$ \\
\hline Demixion zone & {$[29.5-40]$} & -13 \\
Peritectic & 15.9 & -19 \\
Eutectic & 98.5 & -97
\end{tabular}

The phase diagram (Figure 2) shows that ice is in equilibrium with the solution to be treated in a large concentration domain, between 0 and $60 \%$ in weight of acetone. The corresponding temperature range is between $273 \mathrm{~K}$ and $260 \mathrm{~K}$. This is favorable for using the freeze concentration technique to treat wastewaters weakly concentrated in acetone. In the chosen working domain (concentrations between 0 and 30\%), the experimental points of the liquidus curve can be represented by the following correlating equation (Eq. 2):

$$
T_{e q}(K)=-2,24 \cdot 10^{-3} w_{\text {acetone }}{ }^{2}-2,60 \cdot 10^{-1} w_{\text {acetone }}+2,73.10^{2} \quad \text { with } w_{\text {acetone }}<0.3 \quad \text { (Eq. 2) }
$$

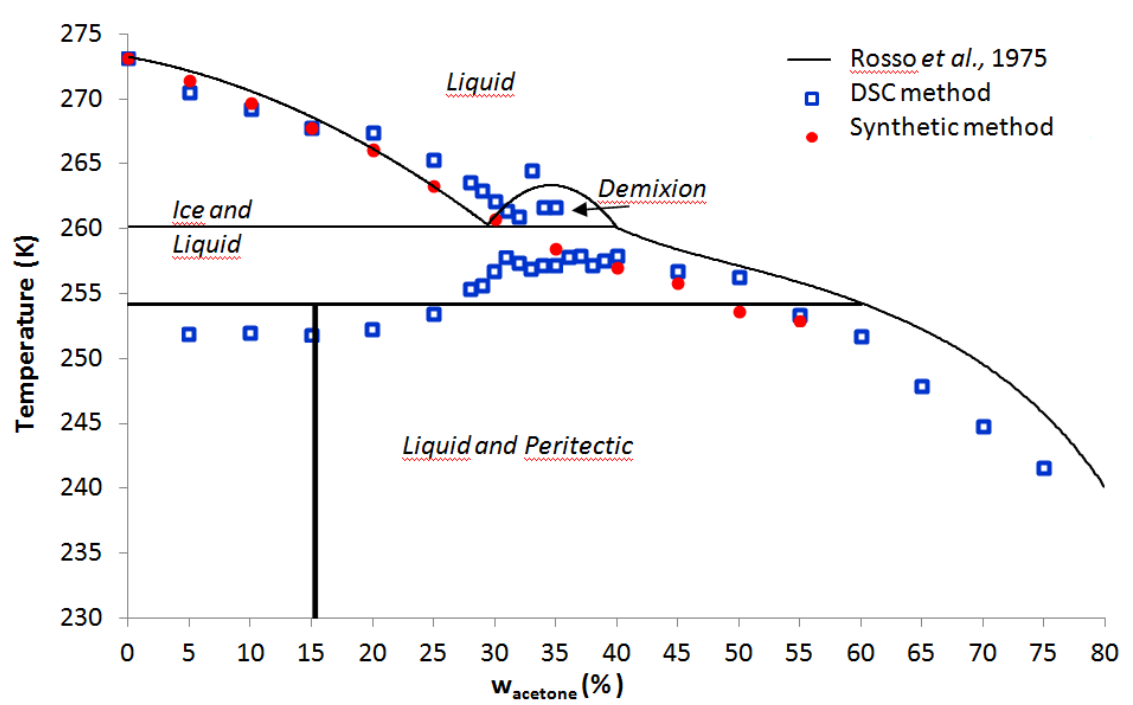

Figure 2: Solid/liquid diagram of water/acetone - Continuous line: literature data (Rosso and Carbonnel, 1975). 


\subsection{Experimental design analysis}

The factorial design study with the Pareto diagram (Figure 3) allows analyzing the effect of each factor on the two response variables, i.e. the impurity concentration $\left(C_{a}\right)$ and the growth velocity $\left(V_{c r}\right)$, as well as the effect of interactions among factors.

This study highlights the important roles played by the cooling rate $\left(V_{R}\right)$ and the initial solute concentration $\left(C_{0}\right)$ on both the acetone concentration in ice $\left(C_{a}\right)$ and the ice growth rate $\left(V_{c r}\right)$. The influence of the parameters on the ice purity will be discussed later. The direct effect of $V_{R}$ on $V_{c r}$, was, of course expected. As concern the effect of $C_{0}$ on $V_{c r}$, it can be explained by the curvature of the liquidus between $5 \%$ and $20 \%$ (Figure 2), which induces a lower growth rate at higher concentration and same cooling rate.

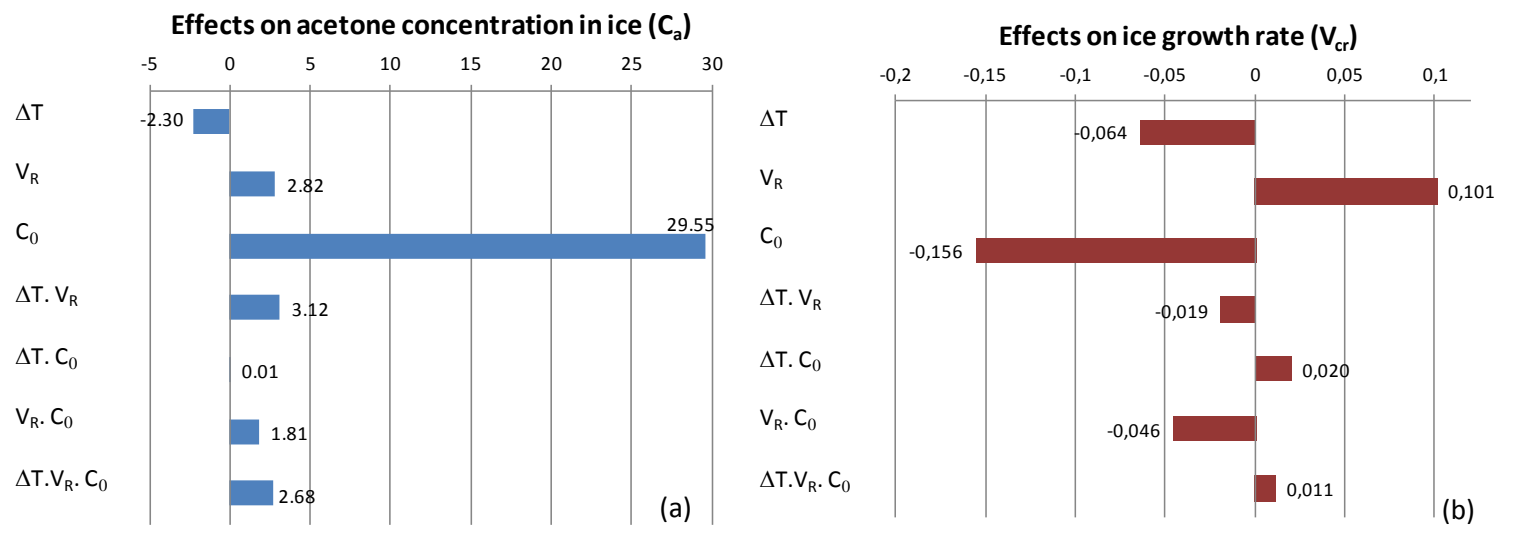

Figure 3: Pareto chart on ice purity and ice growth rate.

After a complete analysis of the experimental design and the remove of non-significant interaction effects, the fitted models for the calculation of $C_{a}$ and $V_{c r}$ are given by the following equations (Eq. 3 and 4 respectively):

$$
C_{a}\left(g . L^{-1}\right)=1.09 .10^{1}-7.53 \Delta T-1.81 .10^{2} V_{R}+3.94 C_{0}+8.06 .10^{1} \Delta T . V_{R}
$$

with a mean absolute error $M A E=2.32 \mathrm{~g} \cdot \mathrm{L}^{-1}$. MAE is the average value of the residuals.

$V_{c r}\left(m m . h^{-1}\right)=2 \cdot 15 \cdot 10^{-1}-4 \cdot 20.10^{-2} \Delta T+7.08 V_{R}-2.50 \cdot 10^{-3} C_{0}-2.43 .10^{-1} V_{R} \cdot C_{0}$ with a mean absolute error MAE $=0.033 \mathrm{~mm} \cdot \mathrm{h}^{-1}$. 
Three experiments (runs 9, 10 and 11, Table 1) were repeated at the center of the domain to estimate the experimental error variance. The experiments 12 and 13 (Table 1 ) were performed to validate the model accuracy with the experimental data.

To complete the study, some additional experiments were conducted (runs 8, 14, 15 and 16) keeping a similar ice growth rate $\left(\mathrm{V}_{\mathrm{cr}} \approx 0.1 \mathrm{~mm} \cdot \mathrm{h}^{-1}\right)$. This comparison highlighted the important role of the initial solute concentration $\left(C_{0}\right)$. Figure $4 a$ shows that, for a same ice growth rate, high initial concentrations $\left(C_{0}\right)$ strongly favor impurity incorporation. We also note a good matching between the model and the experimental data.

On Figure $4 b$, the model is extrapolated at different ice growth rates and the tendency is the same. The impurities contained in the ice are due to liquid inclusions trapped inside of the layer during the ice growth. However, it is quite surprising that, for a given growth rate $\left(V_{c r}\right)$, the acetone concentration in the ice layer does not simply increase linearly with the acetone concentration in the solution. Indeed, we would have expected that the rate of liquid inclusion would be the same, for a given growth rate and regardless of the initial solute concentration. Obviously, this is not the case. Other phenomena may influence the process of liquid inclusions trapped inside of the layer: the presence of air bubbles which may initiate formation of inclusions (Waldschmidt et al., 2011) or an effect of the impurities on growth mechanism. The solution was not preliminary degassed. The effect of air bubbles that can be formed during cooling was not studied but we can expect that all the experiments were conducted in similar conditions. The impurity concentration in the solution at the interface is linked to the occurrence of a concentration gradient (induced by the solute rejection during ice layer growth) and to the existence of convection currents. The effect of the impurities on growth mechanism will be discussed in the next part. 

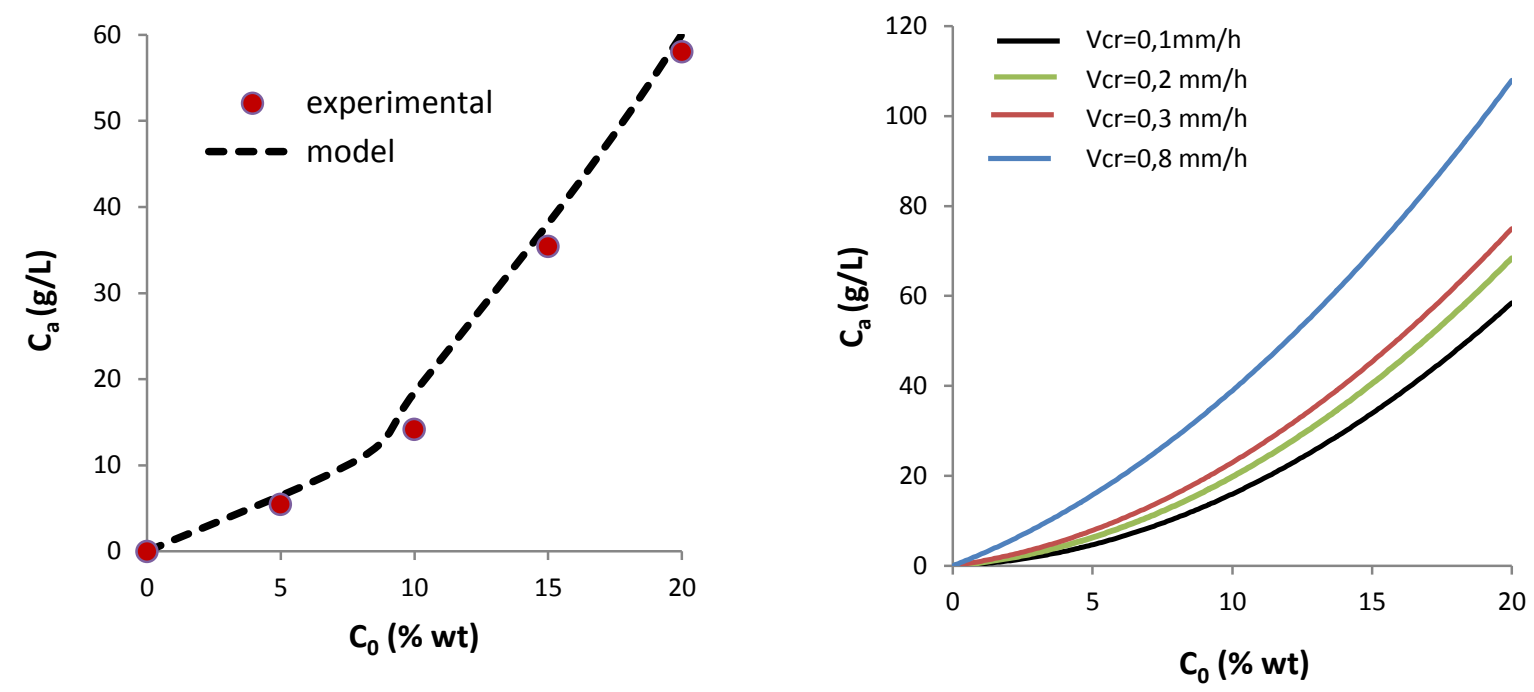

(a)

(b)

Figure 4: Influence of initial concentration $\left(C_{0}\right)$ on acetone concentration in ice $\left(C_{a}\right)$. (a) Comparison between experimental data and modeling $\left(\mathrm{V}_{\mathrm{cr}} \approx 0.1 \mathrm{~mm} \cdot \mathrm{h}^{-1}\right)$; (b) Modeling results at different growth rates $\left(\mathrm{V}_{\mathrm{cr}}\right)$.

\subsection{Microscopic analysis}

Ice layer morphology is directly linked to ice purity and its observation gives interesting insight on the growth mechanism. Optical microscopic analyses in cold room highlight two kinds of possible morphology for ice: monocrystalline (Figure 5a) and polycrystalline (Figure 5b). In the first case, images show a mono-crystalline structure with brine pockets embedded inside of the crystal, whereas in the last case, impurities are trapped in the interstices between the crystals.
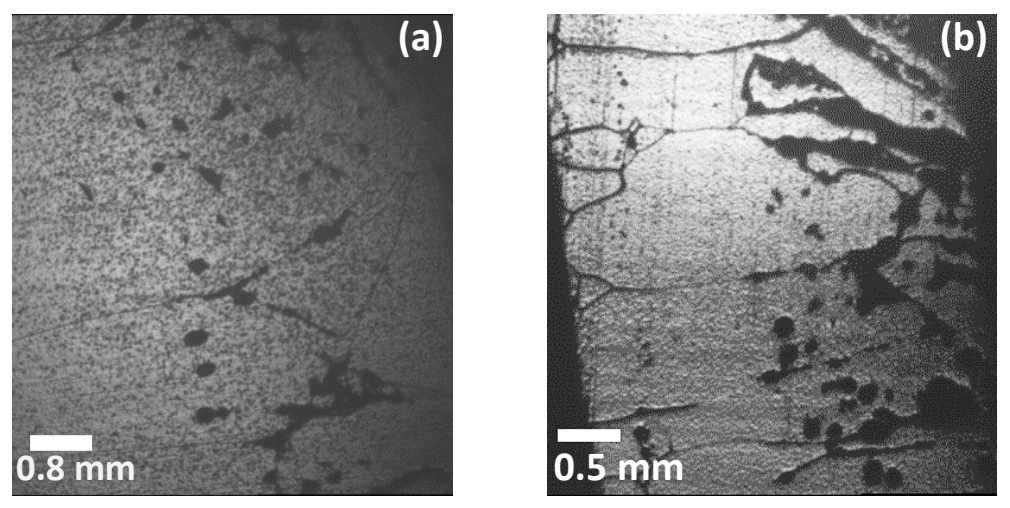

Figure 5: Crystal morphology; (a) mono-pocket solution (run 16) and (b) grain boundary (run 17).

To investigate the influence of initial concentration $\left(C_{0}\right)$, Figure 6 compares the ice structure for three initial acetone concentrations $(5 \%, 10 \%$, and $20 \%$ in weight). Note that the parallel streaks, 
especially in Figure $6 a$ and $6 c$, could be explained by the use of a worn blade during the sample polish with the microtome.

The red line represents the thickness of the seed layer (around $0.5 \mathrm{~mm}$ ). This latter was estimated by weighing the water mass consumed to build this seed layer. Figure $6 a$ and $6 \mathrm{~b}$ show a monocrystalline structure of ice with few localized solution pockets and small air bubbles (black points). However, in the case of higher concentrations (Figure $6 \mathrm{c}$ ), the impurities were mainly trapped in the interstices between the ice crystals, along the grain boundaries. The amount of liquid trapped in the layer was particularly high, when the layer was formed from the solution having the highest concentration.

A change in the layer morphology and thus in the growth mechanism would then explain the observed non linear increase of the acetone concentration in the ice with the acetone concentration in the wastewater solution (Figure 4). Besides, whatever the case, a sweating in depth would be required to drain out the liquid trapped and to improve the ice purity. In a previous work (Rich et al., 2010; Mandri et al., 2011), we observed that the purity reached in the ice after the sweating step was quite independent of the impurity concentration in the ice before sweating. This result can now be explained by the evolution of the ice morphology. Indeed, the sweating process should be particularly efficient in the last case (Figure 6c), thanks to the "canals" existing in the layer. On the contrary, the sweating process should be more difficult in the first case (Figure 6a). As a consequence, it is not surprising that quite similar purity are finally reached, after the sweating step, regardless the purity of the ice, before sweating. 

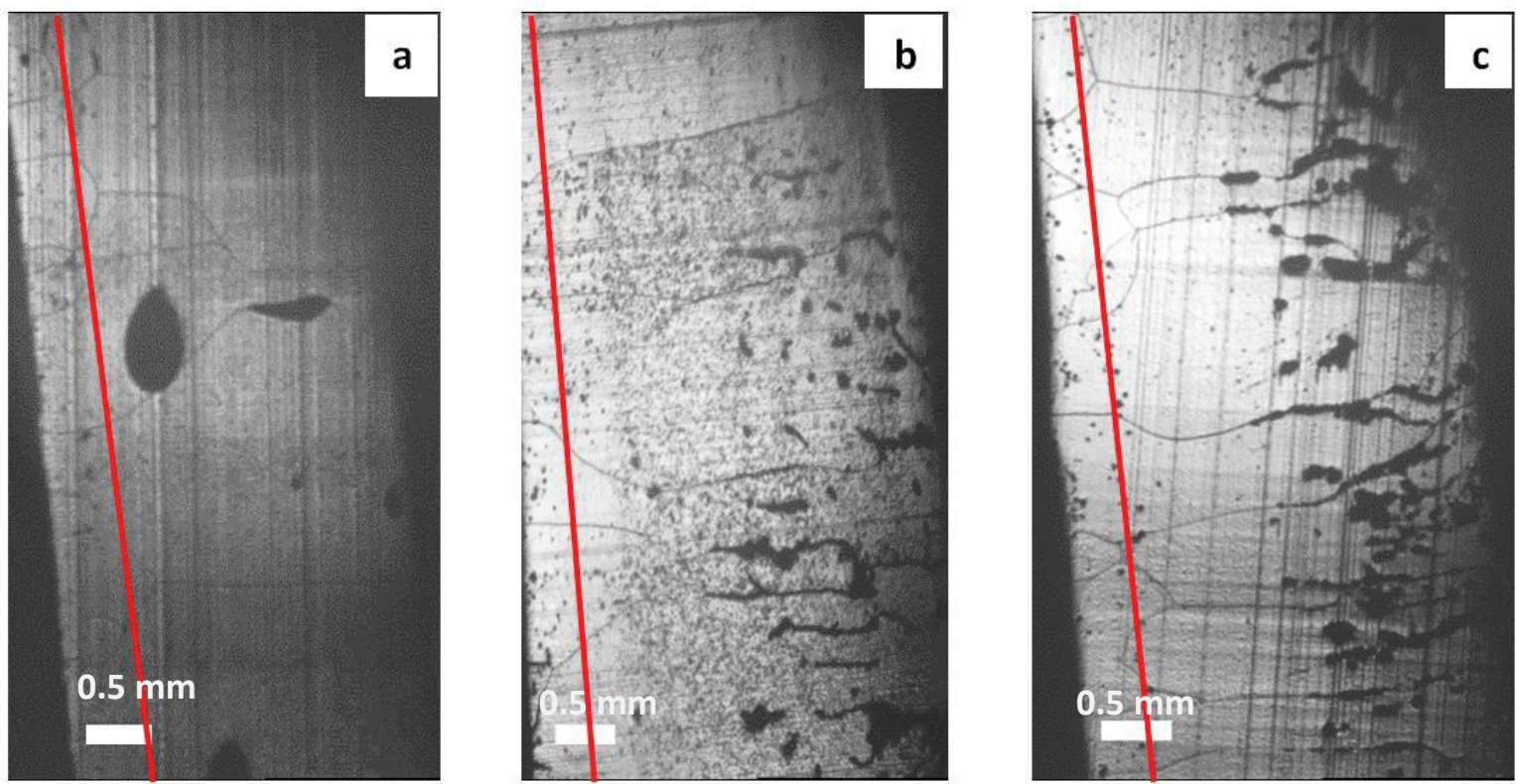

Figure 6: Ice crystal morphology depending on the initial solute concentration; (a) $C_{0}=5 \%$ wt (run 14); (b) $C_{0}=10 \%$ wt (run 15); (c) $C_{0}=20 \%$ wt (run 17). Red line: thickness of the seed layer.

\section{Conclusion}

In this study, industrial wastewater treatment by static melt crystallization on a cold wall was studied. An experimental design was developed to quantify the effects of key parameters on impurity concentration and ice growth rate. The lowest impurity concentration that could be reached was about $3.92 \mathrm{~g} \cdot \mathrm{L}^{-1}$. It was obtained with initial acetone concentration of about $50 \mathrm{~g} . \mathrm{L}^{-1}$ by applying the lowest growth rate $\left(0.1 \mathrm{~mm} \cdot \mathrm{h}^{-1}\right)$ and the highest temperature difference between the cold tube and the tank double jacket. This concentration is not in agreement with the french standards for direct discharge of the water into natural environment (the standard value in France is fixed to $300 \mathrm{mg} \cdot \mathrm{L}^{-1}$ of chemical oxygen demand (COD), corresponding to $136 \mathrm{mg} \cdot \mathrm{L}^{-1}$ of acetone concentration). To reach this objective, the process can be improved by adding a sweating step.

According to previous work (Rich et al., 2010; Mandri et al., 2011), impurity concentration in ice can be divided by 4 , but this factor depends on the ice purity, before sweating. Obviously, the whole process yield, in terms of produced ice mass, is then lower. Further works of melt crystallization in dynamic mode showed that freezing time could be strongly reduced thanks to the agitation. 
Additional work focused on the efficiency of the sweating step, is required to see if water purity satisfying the discharge standards can be reached with a one stage process or if it is necessary to add a second stage of freezing and sweating to satisfy the standards.

A balance has also to be found between the duration of the whole process, its yield and the energy consumption. Overall, the results of the present work show the feasibility of the technique and give a good idea of the operating conditions that can be used for wastewater treatment.

\section{References}

Beierling, T., Ruether, F., 2012, Separation of the isomeric long-chain aldehydes dodecanal/2methylundecanal via layer melt crystallization, Chemical Engineering Science 77, 71-77.

Caillet, A., Cogné, C., Andrieu, J., Laurent, P., Rivoire, A., 2003, Characterization of ice cream structure by direct optical microscopy. Influence of freezing parameters, LWT - Food Science Technology 36 (8), 743-749.

Chen, P., Chen, X. D., Free, K. W., 1999, An experimental study on the spatial uniformity of solute inclusion in ice formed from falling film flows on a sub-cooled surface, Journal of Food Engineering 39 (1), 101-105.

Deshpande, S. S., Cheryan, M., Sathe, S. K., Salunkhe, D. K., Luh, B.S., 1984, Freeze concentration of fruit juices, CRC Critical Reviews in Food Science and Nutrition 20(3), 173-248.

Egolf, P.W., Kitanovski, A., Ata-Caesar, D., Vuarnoz, D., Meili, F., 2008, Cold storage with ice slurries, International Journal of Energy research 32 (3), 187-203.

Halde, R., 1980, Concentration of impurities by progressive freezing, Water Research 14 (6), 575580.

Haasner, T., Kuszlik, A. K., Stadler, R., Ulrich, J., 2001, Surface properties-a key for nucleation in melt crystallization processes, Chemical Engineering and Technology 24 (9), 873-878.

Hirata, T., Ishikawa, M., Yamada, K., 2002, Crystal ice formation of solution and its removal phenomena on inclined cooled plate, International Journal of Refrigeration 25, 190-198.

Htira, T.; Cogné, C.; Gagnière, E.; Mangin, D., 2016, Determination of the Solid-Liquid Phase Diagram of the Binary System Propionic Acid/Water, Journal of Chemical and Engineering Data 61 (2), 806-812. 
Jiang, X.; Li, M.; He, G.; Wang, J., 2014, Research Progress and Model Development of Crystal Layer Growth and Impurity Distribution in Layer Melt Crystallization: A Review, Industrial and Engineering Chemistry Research 53 (34), 13211-13227.

Jusoh, M., Yunus, R.M., Abu Hassan, M.A., 2008, Efficiency study on a new progressive freeze concentration system for freeze wastewater treatment, Jurnal Teknologi 261-270.

Kim, K.-J., 2006, Purification of phosphoric acid from waste acid etchant using layer melt crystallization, Chemical Engineering and Technology 29 (2), 271-276.

Klein, J.-P., Boistelle, R., Dugua, J., 1994, Cristallisation Industrielle-Aspects pratiques; Ed. Techniques Ingénieur. Réference $\mathbf{2} 2788$.

Lorain, O., Thiebaud, P., Badorc, E., Aurelle, Y., 2000, Potential of freezing in wastewater treatment: Soluble pollutant applications, Water Research 35 (2), 541-547.

Mandri, Y., Rich, A., Mangin, D., Abderafi, S., Bebon, C., Semlali, N., Klein, J.P., Bounahmidi, T., Bouhaouss, A., 2011, Parametric study of the sweating step in the seawater desalination process by indirect freezing, Desalination 269 (1-3), 142-147.

Matsuoka, M., Fukuda, T., Takagi, Y., Takiyama, H., 1996, Purification of organic solid solutions by melt crystallization: comparison between layer and suspension crystallization, Journal of Crystal Growth 166 (1-4), 1035-1039.

Miyawaki, O., Liu, L., Shirai, Y., Sakashita, S., Kagitani, K., 2005, Tubular ice system for scale-up of progressive freeze-concentration, Journal of Food Engineering 69, 107-113.

Randall, D.G., Nathoo, J. 2015, A succinct review of the treatment of Reverse Osmosis brines using Freeze Crystallization, Journal of Water Process Engineering 8, 186-194.

Randall, D.G., Nathoo, J., Genceli-Güner F.E., Kramer H.J.M., Witkamp G.J., Lewis A.E. 2012, Determination of the metastable ice zone for a sodium sulphate system, Chemical Engineering Science 77, 184-188.

Rich, A., Mandri, Y., Bendaoud, N., Mangin, D., Abderafi, S., Bebon, C., Semlali, N., Klein, J.P., Bounahmidi, T., Bouhaouss, A., Veesler, S., 2010, Freezing desalination of sea water in a static layer crystallizer, Desalination and water treatment 13 (1-3), 120-127.

Rich, A., Mandri, Y., Mangin, D., Rivoire, A., Abderafi, S., Bebon, C., Semlali, N., Klein, J.P., Bounahmidi, T., Bouhaouss, A., Veesler, S., 2012, Sea water desalination by dynamic layer melt crystallization: Parametric study of the freezing and sweating steps, Journal of Crystal Growth 342,110-116.

Rosso, J.-C.; Carbonnel, L., 1975, Le système binaire eau-acétone, Comptes rendus hebdomadaires des séances de l'Académie des sciences, 699-702.

Shirai, Y., Wakisaka, M., Miyawaki, O., Sakashita, S., 1998, Conditions of producing an ice layer with high purity for freeze wastewater treatment, Journal of Food Engineering 38 (3), 297-308. 
Shirai, Y., Wakisaka, M., Miyawaki, O., Sakashita, S., 1999, Effect of seed ice on formation of tube ice with high purity for a freeze wastewater treatment system with a bubbleflow circulator, Water Research 33 (5), 1325-1329.

Ulrich, J., 2004, Is Melt Crystallization a Green Technology?, Crystal Growth and Design 4, 879-880.

Wakisaka, M., Shirai, Y., Sakashita, S., 2001, Ice crystallization in a pilot-scale freeze wastewater treatment system, Chemical Engineering and Processing: Process Intensification 40, 201-208.

Waldschmidt, A., Couvrat, N., Berton, B., Dupray, V., Morin, S., Petit, S., Coquerel, G.,2011, Impact of Gas Composition in the Mother Liquor on the Formation of Macroscopic Inclusions and Crystal Growth Rates. Case Study with Ciclopirox Crystals, Crystal Growth and Design 11(6), 2463-2470. 